\title{
Genome-Wide Transcript Analysis of Bradyrhizobium japonicum Bacteroids in Soybean Root Nodules
}

\author{
Gabriella Pessi,, ${ }^{1}$ Christian H. Ahrens, ${ }^{2}$ Hubert Rehrauer, ${ }^{2}$ Andrea Lindemann, ${ }^{1}$ Felix Hauser, ${ }^{1}$ \\ Hans-Martin Fischer, ${ }^{1}$ and Hauke Hennecke ${ }^{1}$ \\ ${ }^{1}$ Institute of Microbiology, Eidgenössische Technische Hochschule (ETH), CH-8093 Zürich, Switzerland; ${ }^{2}$ Functional \\ Genomics Center Zürich, Winterthurerstrasse 190, CH-8057 Zürich, Switzerland
}

Submitted 31 May 2007. Accepted 29 June 2007.

\begin{abstract}
The transcriptome of endosymbiotic Bradyrhizobium japonicum bacteroids was assessed, using RNA extracted from determinate soybean root nodules. Results were compared with the transcript profiles of $B$. japonicum cells grown in either aerobic or microaerobic culture. Microoxia is a known trigger for the induction of symbiotically relevant genes. In fact, one third of the genes induced in bacteroids at day 21 after inoculation are congruent with those up-regulated in culture by a decreased oxygen concentration. The other induced genes, however, may be regulated by cues other than oxygen limitation. Both groups of genes provide a rich source for the possible discovery of novel functions related to symbiosis. Samples taken at different timepoints in nodule development have led to the distinction of genes expressed early and late in bacteroids. The experimental approach applied here is also useful for $B$. japonicum mutant analyses. As an example, we compared the transcriptome of wild-type bacteroids with that of bacteroids formed by a mutant defective in the RNA polymerase transcription factor $\sigma^{54}$. This led to a collection of hitherto unrecognized $B$. japonicum genes potentially transcribed in planta in a $\sigma^{54}$-dependent manner.
\end{abstract}

Additional keywords: GeneChip, nitrogen fixation, RpoN.

Rhizobia have two different life-styles, either as free-living soil bacteria or as nitrogen-fixing endosymbionts (also called bacteroids) within root nodules of legume host plants. In a well-balanced physiological interaction, the microsymbiont fixes atmospheric nitrogen and provides ammonia as a nitrogen source to the plant in exchange for a carbon and energy source generated by photosynthesis (Long 2001; Prell and Poole 2006). Nitrogen-fixing bacteroids heavily depend on C4-dicarboxylic acids, which are further respired through the tricarboxylic acid cycle (Lodwig and Poole 2003; Poole and Allaway 2000; Yurgel and Kahn 2004).

Corresponding author: Gabriella Pessi; E-mail: pessi@micro.biol.ethz.ch

The microarray data is available in the National Center for Biotechnology Information Gene Expression Omnibus database and are accessible through GEO Series accession number GSE8478.

* The $\boldsymbol{e}$-Xtra logo stands for "electronic extra" and indicates additional information is available online. Seven supplemental tables and one supplemental figure are published online.
Nodule development is accompanied by a dramatic decline of the free oxygen level in the infected nodule parenchyma, which is a prerequisite for the activity of the oxygen-labile nitrogenase in bacteroids. At first sight, an oxygen-limiting condition appears to oppose the bacteroids' need for ATP production by oxidative phosphorylation in order to fuel the energydemanding nitrogen fixation process (Dixon and Kahn 2004; Downie 2005). Bacteroids solve this dilemma, however, by inducing a symbiosis-specific $c b b_{3}$-type cytochrome oxidase having a very high affinity for oxygen (Preisig et al. 1996) and by coordinating the expression of genes for respiration and nitrogen fixation via sophisticated genetic regulatory networks. In fact, a decreased oxygen tension induces the expression of many rhizobial genes and is believed to be an important signal for their differentiation into bacteroids (Batut and Boistard 1994; Fischer 1994).

The aforementioned are only a few of the massive physiologic changes that occur when free-living rhizobia convert to bacteroids. The availability of several complete rhizobial genome sequences (RhizoBase and RhizoDB websites) now provides an opportunity to study the genetic basis underlying physiological adaptations at a genome-wide scale. Such global views on rhizobial gene expression in symbiosis have been reported for the Sinorhizobium meliloti-Medicago sativa symbiosis (Barnett et al. 2004; Becker et al. 2004; Capela et al. 2006), which is characterized by indeterminate type of nodules (Gage 2004). Much less data are available for the rhizobial gene expression profile in the so-called determinate nodules (Gage 2004), as in the case of the Mesorhizobium loti-Lotus japonicus symbiosis (Uchiumi et al. 2004). In the present study, we report on the first global transcription profiling of $B$. japonicum from determinate soybean nodules. Based on the genome sequence of B. japonicum 110 (9.1 Mb) (Kaneko et al. 2002), a custom-made Affymetrix GeneChip has been designed representing 8,266 annotated $B$. japonicum genes plus intergenic regions (Hauser et al. 2007). Using this array, we monitored global $B$. japonicum transcript levels under free-living aerobic and microaerobic conditions and in symbiosis. It was of interest not only to arrive at a comprehensive list of genes specifically expressed in symbiosis but also to compare the results with the protein expression pattern of B. japonicum isolated from nodules, which has recently been reported (Sarma and Emerich 2005, 2006). Moreover, we assessed how the transcription profile of the $B$. japonicum-Glycine max symbiosis compares with that of the two other symbioses so far studied (S. meliloti-M. sativa, M. loti-L. japonicus). 


\section{RESULTS AND DISCUSSION}

Table 1 presents a survey of all microarray-based transcriptome analyses performed in this study, involving two different B. japonicum strains (wild type and $r p o N_{1+2}$ mutant), three different physiologic conditions (aerobic, microaerobic, and symbiotic growth), and four different timepoints in nodule and bacteroid development $(10,13,21$, and 31 days postinoculation [dpi]). Great care was taken to avoid false results by applying rigorous criteria for normalization procedures and statistical analyses based on numerous biological replicates (discussed below). Furthermore, our previous validations of microarraybased data with reporter gene fusion, quantitative reverse transcription-polymerase chain reaction, and primer-extension techniques have shown that gene expression data, once they have passed these restrictive filters, are trustworthy with a high probability (Hauser et al. 2006; Rudolph et al. 2006; Yang et al. 2006a and b).

Precaution was particularly necessary in comparisons between free-living cells grown in synthetic medium and bacteroids within the highly complex environmental conditions of a nodule (Table 1). Therefore, stringency for nodule data was further tightened by the following means: i) although all $B . j a$ ponicum probe sets on the GeneChip had been pruned against soybean expressed sequence tags (EST), we carried out hybridizations with cDNA derived from nonnodulated soybean roots as control, and only those bacteroid genes were considered as being expressed whose signal value was at least twice as high as the value obtained after hybridization with root cDNA; and ii) genes that were not called "present", i.e., found to be expressed in at least $80 \%$ of the replicates, were excluded. While such stringent criteria helped minimize false positives, the likely loss of several differentially expressed genes with moderate fold-change values had to be acquiesced.

Before taking a global view on genes expressed in symbiosis, two reference data sets were established that list all genes expressed in B. japonicum cells grown in peptone salts-yeast extract (PSY) medium under either aerobic or microaerobic conditions. Of the 8,266 genes represented on the array, a total of 5,439 genes in aerobic and 5,568 genes in microaerobic cultures were found to be expressed (Table 1; Fig. 1). A total of 1,007 genes responded to microoxia with either an increased or a decreased gene expression activity (620 vs. 387 genes, respectively; Table 1). These 1,007 genes are compiled in Supplemental Table 1; they are of potential relevance for symbiosis because microoxia is known to mimic, at least partly, the environmental conditions bacteroids face in root nodules. In fact, we encountered here many of the already known target genes controlled by members of the low-oxygen responsive

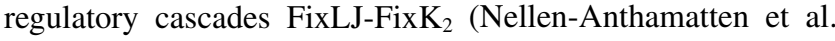
1998) and RegSR-NifA (Bauer et al. 1998; Hauser et al. 2007), such as fixNOQP, fixGHIS, napEDABC, nnrR, nirK, $\operatorname{rpoN}_{1}$, and nifDKEN, nifH, frxA, groESL ${ }_{3}$, respectively.

\section{Global transcript expression pattern in soybean bacteroids} as compared with culture-grown $B$. japonicum.

A much lower number of genes $(2,780)$ were detected as being expressed in soybean bacteroids as compared with cells grown in aerobic culture (Table 1; Fig. 1). This suggests that many genes expressed during growth in synthetic medium may not be needed in symbiosis. Out of these 2,780 genes, a remarkably high number $(2,369)$ are expressed both in symbiosis and in aerobic culture. This leaves 411 genes whose expression appears to occur solely in bacteroids (Fig. 1) (Supplemental Table 2).

To identify genes that are differentially expressed in symbiosis by more than a factor of either \pm 2 , we performed a

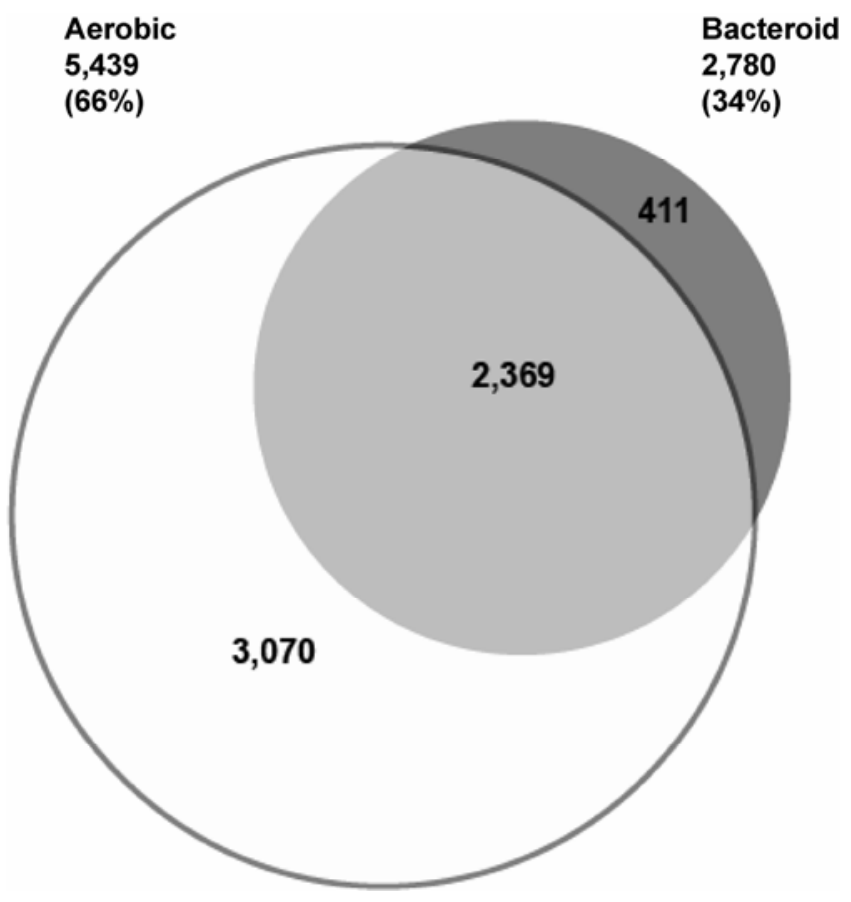

Fig. 1. Venn diagram of genes considered to be "present" (i.e., expressed) in bacteroids and in aerobic cultures. While 5,439 genes were expressed in aerobiosis, only 2,780 are expressed in bacteroids and 411 are expressed solely in bacteroids. Only genes that were present in $80 \%$ of all replicates were considered.

Table 1. Survey of transcriptome analyses performed in this study

\begin{tabular}{|c|c|c|c|c|}
\hline Experimental comparison $^{a}$ & Genes "present" & Differential $^{c}$ & Upregulated $^{\mathrm{d}}$ & Downregulated $^{\mathrm{e}}$ \\
\hline WT free-living aerobic & 5,439 & $\ldots$ & $\ldots$ & $\ldots$ \\
\hline WT free-living microaerobic & 5,568 & $\ldots$ & $\ldots$ & $\ldots$ \\
\hline WT bacteroids ( $21 \mathrm{dpi})$ & 2,780 & $\ldots$ & $\ldots$ & $\ldots$ \\
\hline WT free-living microaerobic vs.aerobic & $\ldots$ & 1,007 & 620 & 387 \\
\hline WT bacteroids ( $21 \mathrm{dpi}$ ) vs. free-living aerobic & $\ldots$ & 2,778 & 692 & 2,086 \\
\hline WT bacteroids 13 dpi vs.10, 21 , and 31 dpi & $\ldots$ & $\ldots$ & 59 & nd \\
\hline WT bacteroids 10 and 13 dpi vs. 21 and 31 dpi & $\ldots$ & $\ldots$ & 57 & 75 \\
\hline$r p o N_{1+2}$ vs. WT, both free-living aerobic & $\ldots$ & 241 & 187 & 54 \\
\hline$r p o N_{1+2}$ vs. WT, both free-living microaerobic & $\ldots$ & 341 & 136 & 205 \\
\hline$r p o N_{1+2}$ bacteroids $v s$. WT bacteroids (both at $21 \mathrm{dpi}$ ) & $\ldots$ & 789 & 339 & 450 \\
\hline
\end{tabular}

${ }^{\mathrm{a}} \mathrm{WT}=$ wild type; $\mathrm{dpi}=$ days postinoculation .

b Number of expressed genes detected in $80 \%$ of the replicates on the array (detection $P$-value $\leq 0.06$ )

c Total number of differentially expressed genes (up- and downregulated) using genes called "present" in bacteroids or in aerobiosis as gene list.

${ }^{\mathrm{d}}$ Number of genes with increased expression in the first condition.

e Number of genes with decreased expression in the first condition; nd = not determined. 
gene-by-gene comparison of the expression profiles in aerobically grown cells and in bacteroids from nodules $(21 \mathrm{dpi})$. 2,778 genes showed a differential expression (Supplemental Table 3), with 692 genes being induced in bacteroids and 2,086 being down-regulated (Table 1). These 2,778 genes were classified according to the 15 categories issued by the Kazusa DNA Research Institute (Kaneko et al. 2002) (Fig. 2). Within the class of 692 bacteroid-induced genes, there was a statistically significant overrepresentation of genes belonging to two of the 15 categories (Fig. 2, on the right), whereas we found an overrepresentation of genes belonging to six of the 15 categories (Fig. 2, on the left) among the 2,086 downregulated genes. This latter observation might reflect the resting stage of mature bacteroids in which a global deceleration of housekeeping functions occurs in favor of symbiosis-specific processes. In fact, decreased expression was observed for genes that are normally active in exponentially growing cells, such as cell-division and motility genes, genes involved in translation (aminoacyl-tRNA synthetases, ribosomal proteins, chain elongation, and peptide release factors), and certain sugar transporters.

Among the 692 genes induced in bacteroids, there are 102 genes with fold-change values $>30$. Their fold-change values were compared with those observed after microaerobic induction in culture (Table 2). While readers may browse through the list and draw their own conclusions, we offer a few comments here. i) The previously known nif and fix genes gather in the overrepresented category "central intermediary metabolism," which nicely confirms the utility of the transcriptomics ap- proach. ii) From the genes belonging to the overrepresented category "transport and binding proteins," the $\bmod A B$ genes (blr6951 to blr6952) and a $\operatorname{modB}$ homolog (blr1719) encode putative molybdate transporters. It seems plausible that bacteroids induce molybdate uptake systems to meet the molybdenum demand for nitrogenase biosynthesis. The importance of efficient molybdate uptake systems for symbiotic nitrogen fixation in $B$. japonicum has already been pointed out previously (Delgado et al. 2006; Maier et al. 1987). iii) Several transcriptional regulators ("regulatory functions" category) showed increased expression in bacteroids (Table 3), and the majority of them (about $75 \%$ ) have, so far, not been implicated or studied in the context of symbiosis. High induction factors are generally not typical for regulatory genes. It comes as a surprise, therefore, that a new LuxR family member (encoded by blr1880) shows a fold-change value of 74.8 (Tables 2 and 3). Also highly expressed are two nodulation genes involved in repression (nolA, nodD2), which is consistent with an overall negative control of nodulation (nod) genes in bacteroids (Loh and Stacey 2003). iv) In the so-called "other categories," we found genes involved in oxidative stress response (e.g., the $a h p C D$-encoded alkylhydroperoxide reductase subunits bll1776 and bll1777; Table 2). This observation nurtures the debate whether or not endosymbiotic rhizobia are oxygen-stressed despite living in conditions of microoxia. Yet, the high cytochrome content in bacteroids and the high concentration of oxygenated leghemoglobin in the infected nodule cells are factors that may contribute to the formation of reactive oxygen species (Pauly et al. 2006).

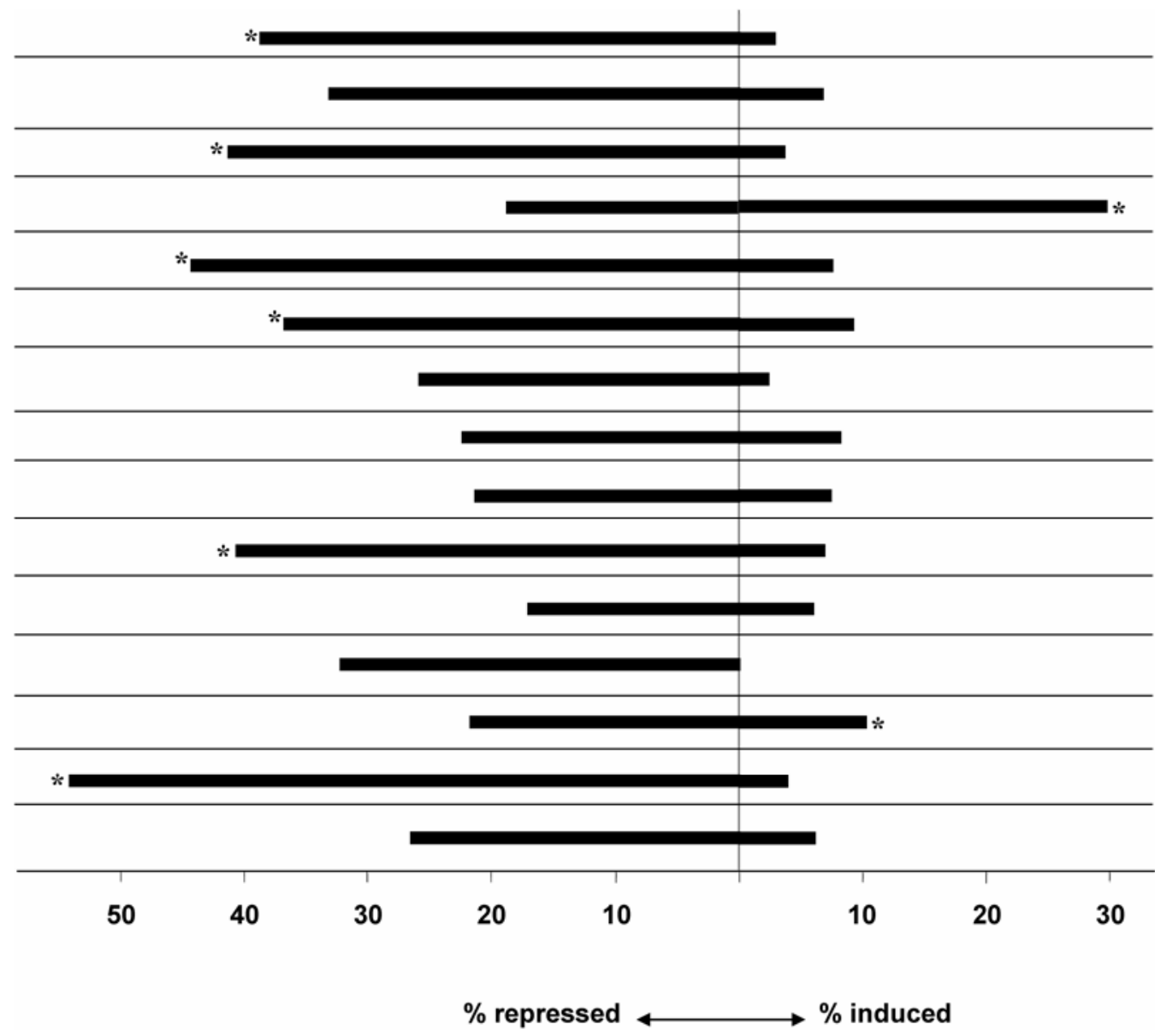

Amino acid biosynthesis
Biosynthesis of cofactors,
prosthetic groups, and carrier

Cell envelope

Central intermediary metabolism

Cellular processes

Energy metabolism

Fatty acid, phospholipid and sterol metabolism

Hypothetical proteins

Other categories

Purines, pyrimidines, nucleosides, and nucleotides

Regulatory functions

DNA replication, recombination, and repair

Transport and binding proteins

Translation

Transcription

Fig. 2. Differentially expressed genes categorized by functional classification according to the Kazusa annotation (RhizoBase website). Percentages of induced and repressed genes are given for the comparison of wild-type bacteroids ( $21 \mathrm{dpi})$ vs. wild-type cells grown aerobically. Percentages are calculated by dividing the number of significantly induced or repressed genes in each category by the total number of retained genes in the corresponding category. Asterisks indicate statistical significance for overrepresented genes in a given category $(P$-value $\leq 0.01)$. 
Since a very low oxygen concentration is a signal for activation of several symbiotic genes in B. japonicum (Sciotti et al. 2003), we compiled all genes that are induced both in microoxia (discussed above) and in symbiosis (Supplemental Table 4). This criterion applies to $233(34 \%)$ of the 692 genes induced in symbiosis, corroborating again the importance of the low-oxygen signal as a trigger of gene expression in bacteroids. One example, a succinate-semialdehyde dehydrogenase-encoding gene (bll3998), which belongs to the functional category "energy metabolism," is singled out here. This enzyme bypasses the 2-oxoglutarate dehydrogenase reaction in the trichloroacetic acid (TCA) cycle and has been proposed to enhance TCA-cycle function during symbiotic nitrogen fixation (Green et al. 2000). The other $66 \%$ of the genes in- duced in bacteroids, not overlapping with the microaerobic stimulon, suggest the existence of signals other than oxygen limitation for gene activation. Interestingly, this group of genes contains $p m t A$, the gene for phosphatidylethanolamine (PE) $\mathrm{N}$ methyltransferase, which converts $\mathrm{PE}$ into phosphatidylcholine and has been shown to be important for an efficient symbiotic interaction of $B$. japonicum with its host plant (Minder et al. 2001).

The chromosomal distribution of genes that are up-regulated in bacteroids was evaluated (Fig. 3; discussed below). The data showed that $27 \%$ of the bacteroid-induced genes are contained within the 410-kb "symbiotic region" previously defined by Göttfert and associates (2001) and partially overlap with the extended 681-kb "symbiotic island" proposed by Kaneko and

Table 2. The 102 most highly induced genes (fold change $>30$ ) in wild-type bacteroids when aerobically grown wild-type cells were used as reference

\begin{tabular}{|c|c|c|c|c|}
\hline \multirow[b]{2}{*}{ Gene number ${ }^{a}$} & \multirow[b]{2}{*}{ Description $^{b}$} & \multirow[b]{2}{*}{ Gene name ${ }^{c}$} & \multicolumn{2}{|c|}{ Fold change } \\
\hline & & & Bacteroids vs. aerobic $^{\mathrm{d}}$ & Microaerobic vs. aerobic $^{\mathrm{e}}$ \\
\hline blr2106 & L-ectoine synthase & ectC & 1201.0 & 19.7 \\
\hline blr2143 & Similar to cytochrome $\mathrm{P} 450$-family protein & - & 1008.0 & - \\
\hline bsr2010 & - & - & 358.7 & 4.7 \\
\hline blr8234 & - & - & 316.8 & - \\
\hline blr2131 & Probable oxygenase & - & 298.2 & 15.9 \\
\hline blr2146 & Dehydrogenase & - & 243.3 & - \\
\hline bl11767 & - & - & 242.0 & 3.8 \\
\hline bs11637 & - & - & 215.9 & - \\
\hline bl12047 & - & - & 208.7 & - \\
\hline bl11858 & - & - & 207.9 & - \\
\hline blr2011 & - & - & 203.5 & - \\
\hline blr3719 & - & - & 182.4 & - \\
\hline blr1850 & - & - & 177.7 & 4.0 \\
\hline blr2071 & Similar to inosamine-phosphate amidinotransferase & - & 170.8 & 4.5 \\
\hline bl11777 & Alkyl hydroperoxide reductase & $\operatorname{ahpC}$ & 169.8 & 7.8 \\
\hline bl12065 & Carbonic anhydrase & icfA & 156.5 & - \\
\hline blr1638 & - & - & 155.0 & - \\
\hline blr2132 & - & - & 147.7 & 7.1 \\
\hline bl12004 & - & - & 146.8 & - \\
\hline blr1964 & Putative sugar hydrolase & - & 145.0 & - \\
\hline blr1755 & Rhizobium etli iscN homolog & - & 138.7 & 7.0 \\
\hline blr1726 & - & - & 137.6 & - \\
\hline blr6951 & Molybdenum $\mathrm{ABC}$ transporter molybdate-binding protein & $\bmod A$ & 128.0 & 18.7 \\
\hline bl11981 & - & - & 125.8 & - \\
\hline bsr1758 & - & - & 125.5 & - \\
\hline blr1765 & Ferredoxin & fer2 2 & 124.9 & - \\
\hline bl11754 & - & - & 120.9 & 5.5 \\
\hline bl11906 & $N$-acetyltransferase homolog $\mathrm{NrgA}$ & $n r g A$ & 120.0 & 8.3 \\
\hline blr1719 & Molybdenum transport system permease protein & $\bmod B$ & 119.5 & - \\
\hline bl11872 & - & - & 115.4 & 4.2 \\
\hline blr1743 & Nitrogenase molybdenum-iron protein alpha chain & nifD & 107.3 & 13.8 \\
\hline blr2144 & Cytochrome P-450 B-1 & CYP112 & 107.0 & 7.6 \\
\hline blr1744 & Nitrogenase molybdenum-iron protein beta chain & nifK & 106.1 & 12.4 \\
\hline bsr1757 & Nitrogen fixation protein & fixU & 105.4 & 4.8 \\
\hline bsr1760 & Ferredoxin-like protein & frxa & 105.3 & 4.0 \\
\hline bl12063 & Phenolhydroxylase homolog & $\mathrm{nrgC}$ & 105.0 & 4.4 \\
\hline blr1769 & Dinitrogenase reductase protein & nifH & 96.2 & 7.0 \\
\hline blr1771 & Nitrogenase stabilizing/protective protein & $n i f W$ & 95.2 & 2.2 \\
\hline bl11944 & - & - & 89.7 & 3.8 \\
\hline bl11875 & - & - & 85.7 & - \\
\hline blr1770 & Molybdenum processing protein & nifQ & 85.0 & 3.2 \\
\hline blr1853 & Cytochrome P450 family protein & - & 84.6 & - \\
\hline bl12060 & GroES3 chaperonin & groES & 83.0 & 4.4 \\
\hline bl12066 & - & - & 81.4 & - \\
\hline blr1756 & Nitrogenase metalloclusters biosynthesis protein & nifS & 78.7 & 4.1 \\
\hline bl11776 & Alkyl hydroperoxide reductase & ahpD & 78.6 & 4.1 \\
\hline bsr1739 & Ferredoxin & - & 76.0 & 8.8 \\
\hline \multirow[t]{2}{*}{ bl12125 } & Probable dioxygenase & - & 75.0 & - \\
\hline & & & & Continued on following pa \\
\hline
\end{tabular}

\footnotetext{
${ }^{a}$ Nomenclature according to Kaneko and associates (2002).

${ }^{\mathrm{b}}$ Gene description according to Kaneko and associates (2002). - indicates unknown or hypothetical proteins.

${ }^{\mathrm{c}}$ Gene name according to the EMBL-EBI database.

${ }^{\mathrm{d}}$ Comparing bacteroids and aerobically grown cells.

${ }^{\mathrm{e}}$ Comparing microaerobically and aerobically grown cells; - indicates the gene was not differentially expressed.
} 
associates (2002). Two other regions also had an above-average content of genes that are up-regulated in symbiosis (Fig. 3). Region I carries genes for several monooxygenases (blr3677 through blr3679), a dicarboxylate transporter DctA (blr3723), and the poly- $\beta$-hydroxybutyrate biosynthetic enzymes (blr3724 and blr3725); region II encodes the hydrogen uptake system (bll6927 to bll6949), the molybdate transport complex (blr6951 through blr6953), and the periplasmic nitrate reductase (bsr7036 through blr7040). The accumulation of symbiotically relevant genes in the "symbiotic island" is correlated with a significantly lower $\mathrm{G}+\mathrm{C}$ content, whereas the correlation between a lower $\mathrm{G}+\mathrm{C}$ content and the high density of up-regulated genes is less compelling in regions I and II (Fig. 3).
Genes expressed early and late in bacteroid development.

The in-nodule gene expression inventory reported so far concerned bacteroids at $21 \mathrm{dpi}$, a timepoint when maximal nitrogen-fixation activity had been routinely observed under the plant-cultivation conditions used in our laboratory. In order to possibly identify genes expressed early and late in bacteroid development, we analyzed the global transcription profile in a nodulation timecourse experiment. Soybean nodules were harvested at $10,13,21$, and $31 \mathrm{dpi}$, having relative symbiotic nitrogen fixation activities of 9, 95, 100, and 61\%, respectively, and RNA was extracted from all samples for microarray analysis. A clustering analysis (Fig. 4) led to the following classification: i) a cluster of genes maximally expressed at 10 and 13 dpi, ii) genes maximally induced at $13 \mathrm{dpi}$, and iii) a cluster of

Table 2. Continued from preceding page

\begin{tabular}{|c|c|c|c|c|}
\hline \multirow[b]{2}{*}{ Gene number ${ }^{\mathrm{a}}$} & \multirow[b]{2}{*}{ Description $^{\text {b }}$} & \multirow[b]{2}{*}{ Gene name $^{c}$} & \multicolumn{2}{|c|}{ Fold change } \\
\hline & & & Bacteroids vs. aerobic $^{d}$ & Microaerobic vs. aerobic $^{\mathrm{e}}$ \\
\hline blr1880 & Transcriptional regulatory protein LuxR family & - & 74.8 & - \\
\hline blr1851 & - & - & 74.2 & - \\
\hline blr1759 & FeMo cofactor biosynthesis protein & nifB & 74.1 & 2.9 \\
\hline blr1879 & - & - & 72.0 & - \\
\hline bll3193 & _- & - & 65.1 & - \\
\hline blr1745 & Nitrogenase molybdenum-cofactor synthesis protein & nifE & 62.9 & 4.7 \\
\hline bl12009 & - & - & 61.1 & - \\
\hline blr6952 & Molybdenum $\mathrm{ABC}$ transporter permease protein & $\bmod B$ & 59.7 & 6.0 \\
\hline blr2133 & - & - & 58.7 & 5.3 \\
\hline bll6634 & Probable phosphatidylethanolamine $N$-methyltransferase & $p m t A$ & 58.1 & - \\
\hline blr3677 & Putative monooxygenase component & - & 56.9 & - \\
\hline blr2145 & Cytochrome P-450 BJ-3 & CYP114 & 55.0 & 3.3 \\
\hline blr3675 & Putative alcohol dehydrogenase & - & 54.4 & - \\
\hline blr1901 & - & - & 52.2 & - \\
\hline bsl1857 & - & - & 50.6 & - \\
\hline blr1686 & Putative aminotransferase protein & - & 48.2 & - \\
\hline blr2134 & - & - & 47.9 & 3.3 \\
\hline blr1746 & Nitrogenase molybdenum-cofactor synthesis protein & nifN & 47.8 & 2.9 \\
\hline blr1773 & Electron transfer flavoprotein alpha chain & fixB & 47.6 & 2.2 \\
\hline bl12059 & GroEL3 chaperonin & groEL & 47.4 & 2.9 \\
\hline bl12067 & Nodule formation efficiency protein & $n f e C$ & 47.4 & - \\
\hline bl11634 & - & - & 45.1 & - \\
\hline blr3679 & Putative monooxygenase component & - & 44.8 & - \\
\hline blr1954 & - & - & 43.6 & _- \\
\hline bll2049 & Anthranilate phosphoribosyltransferase & $\operatorname{trpD}$ & 43.3 & - \\
\hline bl11979 & - & - & 42.1 & - \\
\hline bsr2005 & - & - & 41.7 & - \\
\hline bl12085 & - & - & 41.3 & - \\
\hline blr1852 & Similar to pantoate-beta-alanine ligase & - & 39.1 & - \\
\hline blr2108 & Probable peptide synthetase & - & 39.0 & - \\
\hline bsr2765 & $c b b 3$ oxidase, subunit IV & fix $Q$ & 38.3 & 59.6 \\
\hline bl12018 & Similar to $\mathrm{ABC}$ transporter, amino acid binding protein & - & 38.3 & - \\
\hline blr1774 & Flavoprotein & fixC & 38.1 & - \\
\hline blr4988 & - & - & 37.7 & - \\
\hline bl16950 & Putative pyrophosphorylase & $\bmod D$ & 36.3 & - \\
\hline bll2017 & Similar to $\mathrm{ABC}$ transporter, amino acid binding protein & - & 36.2 & - \\
\hline bl16942 & Uptake hydrogenase precursor & hupS & 35.1 & - \\
\hline bs12048 & - & - & 35.1 & - \\
\hline bl15734 & $\mathrm{ABC}$ transporter nitrate-binding protein & $n r t A$ & 34.4 & - \\
\hline blr1747 & Iron-molybdenum cofactor processing protein & nifX & 33.5 & - \\
\hline blr1761 & Iron-sulfur cofactor synthesis protein & nifZ & 33.2 & 2.1 \\
\hline blr3680 & - & - & 33.1 & - \\
\hline bll2515 & Similar to pyruvate phosphate dikinase & _- & 32.9 & - \\
\hline blr2611 & - & - & 32.8 & 27.5 \\
\hline bl12046 & - & - & 32.7 & - \\
\hline bs12020 & - & - & 32.6 & - \\
\hline bl16941 & Uptake hydrogenase large subunit & hирL & 32.2 & - \\
\hline blr2038 & Electron transfer flavoprotein beta chain & fixA & 31.9 & - \\
\hline bsr1907 & - & - & 31.6 & - \\
\hline bsr1764 & _- & - & 30.9 & - \\
\hline blr2763 & Cytochrome $c$ oxidase ( $c b b 3$ type) & fixN & 30.6 & 52.2 \\
\hline blr1748 & - & - & 30.4 & 2.7 \\
\hline bll2019 & Transcriptional regulatory protein MerR family & nolA & 30.2 & -2.0 \\
\hline blr1854 & - & - & 30.0 & - \\
\hline
\end{tabular}


genes expressed more highly at 21 and $31 \mathrm{dpi}$. The complete list of genes falling into these classes is provided in Supplemental Table 5. These genes might be useful reference markers for nodule and bacteroid development.

Genes for a type III secretion system (T3SS; blr1812 to blr1822) were among those that are maximally induced at 10 and 13 dpi. Although T3SS genes are not essential for soybean nodulation, they are known to be coregulated to a large extent with early nod genes (Krause et al. 2002). The class of 59 genes whose expression was maximal at 13 dpi contained a number of transporter genes, including several putative phosphate transport operons such as blr1092 to blr1097, suggesting

Table 3. The 39 transcriptional regulators induced in wild-type bacteroids compared with wild-type cells grown in aerobic culture

\begin{tabular}{|c|c|c|c|}
\hline Gene number ${ }^{a}$ & Description $^{b}$ & Gene name $^{\mathrm{c}}$ & Fold change $^{d}$ \\
\hline blr1880 & Transcriptional regulatory protein LuxR family & - & 74.8 \\
\hline bl12019 & Transcriptional regulatory protein MerR family & nolA & 30.2 \\
\hline bll2021 & Transcriptional regulatory protein LysR family & nodD2 & 19.5 \\
\hline blr5805 & Transcriptional regulatory protein Crp family & - & 19.4 \\
\hline blr1216 & Transcriptional regulatory protein Ferric uptake regulator family & - & 10.7 \\
\hline blr0612 & Nitrogen regulatory protein PII & $g \ln K$ & 8.9 \\
\hline blr4466 & Transcriptional regulatory protein $\mathrm{AraC}$ family & - & 8.4 \\
\hline blr1847 & VirK protein homolog & _- & 7.5 \\
\hline bl12604 & Transcriptional regulatory protein MarR family & - & 5.8 \\
\hline blr6408 & Transcriptional regulatory protein AraC family & - & 5.8 \\
\hline bl13386 & Transcriptional regulatory protein AraC family & - & 5.6 \\
\hline bl16414 & Transcriptional regulatory protein LuxR family & - & 5.5 \\
\hline bl10966 & Two-component hybrid sensor and regulator & _- & 4.6 \\
\hline blr7666 & Transcriptional regulatory protein AraC family & - & 3.8 \\
\hline bl12465 & MoxR family protein & - & 3.4 \\
\hline blr1096 & Phosphate regulon, two-component response regulator & phoB & 3.3 \\
\hline blr2037 & Nif-specific regulatory protein & nifA & 3.2 \\
\hline bl15291 & Transcriptional regulatory protein ArsR family & - & 3.1 \\
\hline bl12109 & Transcriptional regulatory protein Crp family & fixK & 3 \\
\hline blr2285 & Two-component response regulator & - & 3 \\
\hline blr3685 & Transcriptional regulatory protein Fis family & - & 3 \\
\hline blr5345 & Transcriptional regulatory protein ArsR family & _ & 2.9 \\
\hline blr5735 & Transcriptional regulatory protein Fis family & - & 2.9 \\
\hline bl11688 & Probable suppressor protein & - & 2.7 \\
\hline bll6061 & Transcriptional regulatory protein Crp family & fixK & 2.7 \\
\hline bl12023 & Transcriptional regulatory protein LysR family & nodD1 & 2.6 \\
\hline blr0347 & Transcriptional regulatory protein MarR family & - & 2.5 \\
\hline bsr6672 & Transcriptional regulatory protein Fis family & - & 2.5 \\
\hline bl17016 & Two-component hybrid sensor and regulator & _ & 2.5 \\
\hline bl17588 & Transcriptional regulatory protein AsnC family & - & 2.5 \\
\hline bl12758 & Two-component response regulator & - & 2.4 \\
\hline blr5860 & Transcriptional regulatory protein GntR family & _- & 2.4 \\
\hline bl11179 & Two-component sensor histidine kinase & - & 2.3 \\
\hline blr3443 & Transcriptional regulatory protein TetR family & _- & 2.3 \\
\hline blr4773 & Two-component hybrid sensor and regulator & $n w s A$ & 2.3 \\
\hline bll1150 & Transcriptional regulatory protein LysR family & - & 2.2 \\
\hline bl12786 & Transcriptional regulatory protein LysR family & - & 2.2 \\
\hline bl16060 & Putative catabolite gene activator & _- & 2.2 \\
\hline bl17017 & Transcriptional regulatory protein LuxR family & - & 2.1 \\
\hline
\end{tabular}

${ }^{a}$ Nomenclature according to Kaneko and associates (2002).

${ }^{\mathrm{b}}$ Gene description according to Kaneko and associates (2002).

${ }^{c}$ Gene name according to the EMBL-EBI database.

${ }^{\mathrm{d}}$ Fold change of expression, comparing bacteroids and aerobically grown cells.

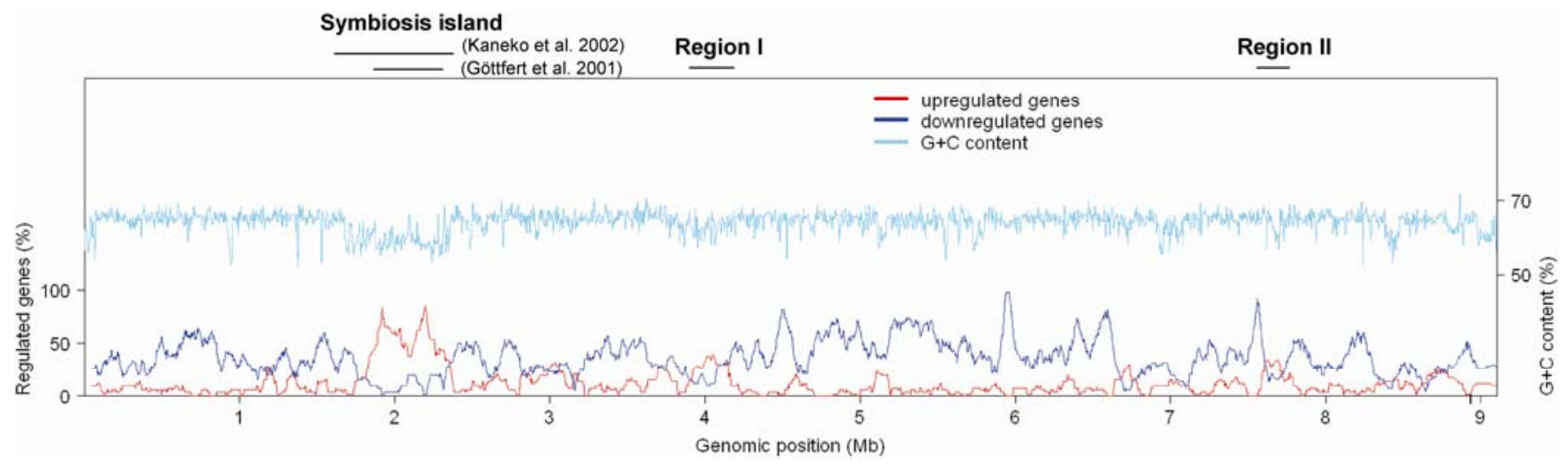

Fig. 3. Plot of the linearized Bradyrhizobium japonicum genome and a summary of differential gene expression at all regions in symbiotic bacteroids relative to aerobic cultures. Across the entire genome, the track in red marks the percentage of upregulated genes and in blue, the percentage of downregulated genes. The $\mathrm{G}+\mathrm{C}$ content is shown in cyan. All percentages were computed with a sliding window algorithm that considered 50 genes at a time. Note the most prominent upregulation in the symbiosis island and in regions I and II. 
that young bacteroids require an adequate phosphate supply. A previous global study on the Pho regulon in S. meliloti (Krol and Becker 2004) showed that phosphate starvation causes oxidative stress; hence, a high-affinity phosphate transporter might help to overcome such an adverse condition. The class of 75 genes specifically induced in mature nodules (21 and 31 dpi) again contained many transporter genes. Among genes preferentially expressed late, there are, for example, some that appear to be involved in uptake, activation, and utilization of sulfate or sulfonate, suggesting that fully developed bacteroids may run into sulfur-limiting conditions. In fact, the Escherichia coli ssuD-encoded alkanesulfonate monooxygenase, for which there are two homologs in B. japonicum, is expressed only under conditions of sulfate or cysteine starvation (Eichhorn et al. 2000).

\section{Comparing transcriptomics with proteomics.}

Sarma and Emerich $(2005,2006)$ have compared the proteomes of culture-grown B. japonicum and soybean bacteroids by two-dimensional gel electrophoresis. Of the 289 proteins they detected under aerobic growth conditions, 277 (96\%) were found to be expressed in our study. Another 87 proteins were detectable exclusively in the bacteroid state (Sarma and Emerich 2005). It was gratifying to see, with our transcriptomics approach, that 69 out of those 87 proteins were encoded by genes whose expression was found in bacteroids and 29 were among those that we found to be transcriptionally up-regulated (Supplemental Table 6). Among the 69 bacteroid-specific genes or gene products that were congruent in both studies, we found not only nitrogenase - as expected-but also three cytochromes P450, two chaperonins $\left(\mathrm{GroES}_{3}\right.$ and $\left.\mathrm{GroEL}_{3}\right)$, and the $p h b C$-encoded poly- $\beta$-hydroxybutyrate polymerase. The additional 18 proteins identified by Sarma and Emerich (2005, 2006) are encoded by genes that were expressed but failed to pass our stringent filtering criteria for expression. Despite a remarkable degree of overlap between the transcriptomics and proteomics data, only the combination of both techniques may yield the information needed to ever reveal the full complement of genes or proteins expressed in bacteroids. In particular, the ability of proteomics technologies to accurately measure the expression level of proteins and detect post-translational modifications that effect protein function, activity state, and localization provide insights that are not amenable by transcriptomics studies. On the other hand, global transcriptomics studies have the benefit to detect expression levels for genes encoding proteins of low abundance and thus provide a more complete list of the elements.

\section{Comparison of transcriptomics data from three rhizobial systems.}

We compared our global transcription study on B. japonicum with similar studies on bacteroids of $S$. meliloti (Barnett et al. 2004; Becker et al. 2004; Capela et al. 2006) and M. loti (Uchiumi et al. 2004) and found a high concordance. Out of the $2,778 \mathrm{~B}$. japonicum genes that are differentially expressed in symbiosis, 1,229 have orthologous genes in S. meliloti (National Center for Biotechnology Information [NCBI] genome comparison website). While the three $S$. meliloti studies reported varying numbers of regulated genes, the percentage of genes found to be regulated alike in B. japonicum ranged between 80 and $92 \%$. We observed that concordance of our study was most pronounced with Barnett and associates (2004) who, interestingly, used a similar type of Affymetrix array. Examples of genes that were induced in the B. japonicum-Glycine max symbiosis but repressed in the $S$. meliloti-M. sativa nodules include phosphate/phosphonate transport systems (phoCDE, pstABC), an ABC-type transporter (bll4544), and a cold-shock protein (bsr7468). Conversely, genes that were repressed in $B$. japonicum bacteroids but induced in at least two of the three $S$. meliloti studies include the citrate synthase ( $g l t A ;$ blr4839) and a putative outer-membrane protein (blr4700). Of the 2,778 genes that are differentially expressed in bacteroids of $B$. japonicum, 1,261 have orthologs in M. loti. A total of $84 \%$ of the genes differentially expressed in $M$. loti-L. japonicus nodules and having a $B$. japonicum ortholog were also found to be similarly regulated in our study. The differences uncovered in the three symbiotic systems might be trivial consequences of the different experimental conditions applied (e.g., medium composition, nodule age) or due to disparate normalization and analysis criteria or both. On the other hand, they might reflect the different environmental conditions $B$. japonicum meets in determinate nodules vs. $S$. meliloti in the indeterminate nodules. While the regulation of a large percentage of orthologs is conserved in the three symbiosis systems, we find a large proportion of the remaining genes have no detectable homolog and are specific to B. japonicum.

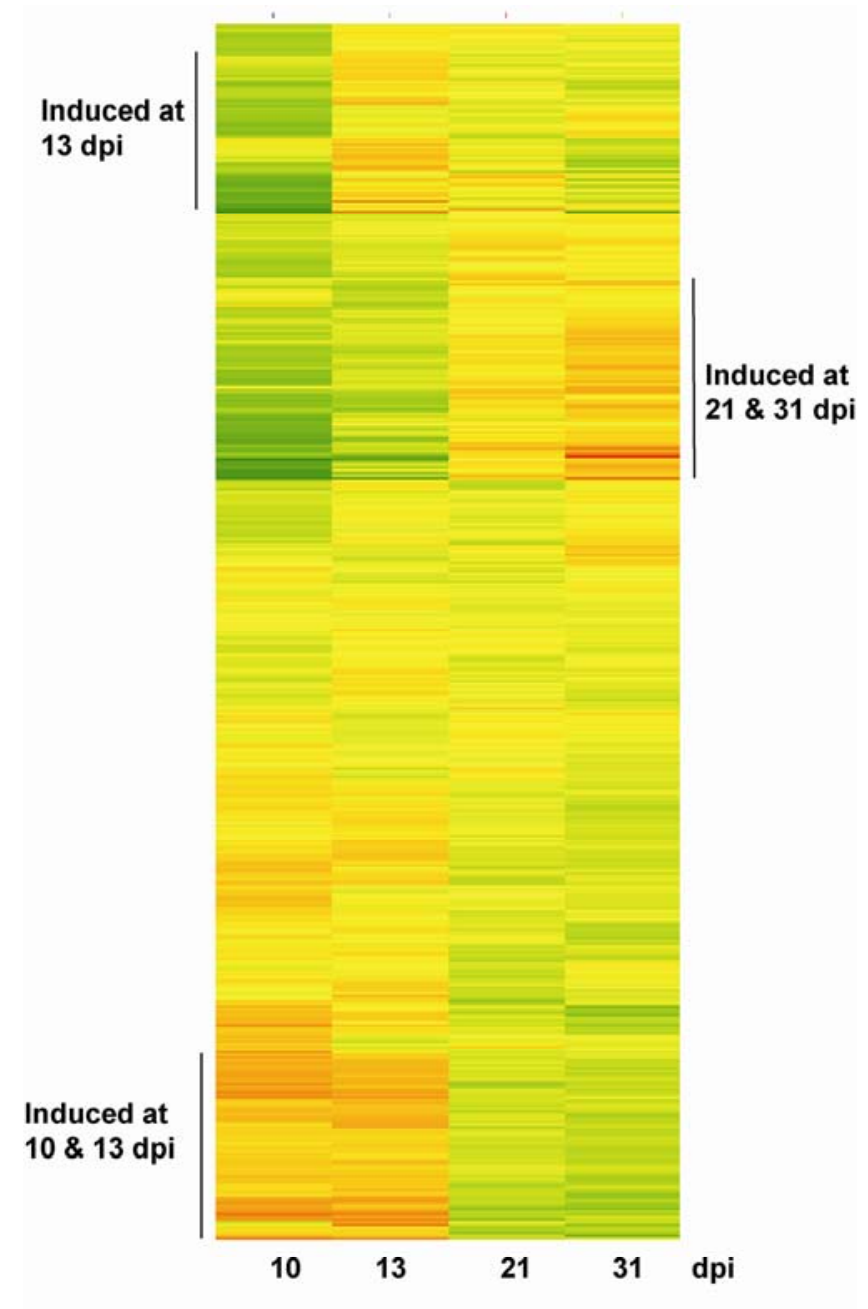

Expression level:

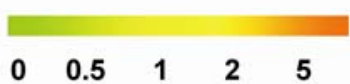

Fig. 4. Hierarchical clustering of changes in gene expression during nodule development. Gene expression profiles were determined from Bradyrhizobium japonicum-Glycine max nodules at 10 and 13 or 21 and 31 days postinoculation (dpi). The color code for expression levels is shown at the bottom. 
In-nodule transcriptome analysis of a $\mathrm{Nod}^{+} \mathrm{Fix}^{-}$mutant.

Research in our own laboratory as well as in other laboratories has generated a large collection of B. japonicum $110 \mathrm{mu}-$ tant derivatives that are still able to elicit soybean nodules but are unable to carry out symbiotic nitrogen fixation $\left(\mathrm{Nod}^{+} \mathrm{Fix}^{-}\right.$ phenotype). We were interested in exploring whether our transcriptomics approach could be extended to nodules infected by such mutants. The transcription factor $\sigma^{54}$-deficient mutant (strain N50-97; genotype $\operatorname{rpoN}_{1}^{-}, \operatorname{rpoN}_{2}^{-}$) was chosen for this purpose because i) it still forms a discernible number of bacteroids in spite of its pleiotropic phenotype (Kullik et al. $1991)$, ii) $\sigma^{54}$ is the key sigma factor for transcription of nitrogen fixation genes, so the mutant can be used to define the $\sigma^{54}$ regulon, iii) all genes transcribed with the help of $\sigma^{54}$ depend on an activator protein, and iv) the genes belonging to the $\sigma^{54}$ regulon in anaerobically grown $B$. japonicum have already been studied extensively (Hauser et al. 2007). Here, we compared the transcriptome in $r p o N_{1+2}$ mutant bacteroids with that of wild-type bacteroids, both at 21 dpi. For reference, similar mutant vs. wild type comparisons were also done in free-living cells grown aerobically and microaerobically (Table 1).

A total of 789 genes were found to be differentially expressed in rpoN mutant-infected nodules as compared with nodules infected with the $B$. japonicum wild type. A complete list of these genes is provided in Supplemental Table 7. As a consequence of the missing $\sigma^{54}$, the expression of 450 genes is decreased, whereas 339 genes respond to this change with an increased expression, and-remarkably-the $\sigma^{54}$ regulon in symbiosis (789 genes) is larger than the $\sigma^{54}$ regulons in microaerobic and aerobic cultures (341 and 241 genes, respectively; Table 1). This underscores the symbiotic importance of $\sigma^{54}$. The remarkably high number of genes with increased expression in nodules infected by a $r p o N_{1+2}$ mutant could be due to indirect cryptic effects.

Of the $450 \sigma^{54}$-dependent genes, 96 are potentially transcribed by the RNA polymerase- $\sigma^{54}$ complex, because we identified $\sigma^{54}$ promoters $\left(-24 /-12\right.$ consensus sequences) in the $5^{\prime}$-flanking DNA to the first gene of each transcription unit (not shown). Expression of 35 of these 96 genes also depended on $\sigma^{54}$ in microaerobic culture. Almost all of them have recently been shown to be activated by the low oxygen-responsive enhancer-binding protein NifA (Hauser et al. 2007). The symbiotic induction of the other 61 potential RpoN targets (Table 4) is new and different. Interestingly, several of the newly identified potential RpoN targets lack a NifA binding site in the promoter region (e.g., the blr3719 to blr3722 genes encoding a putative 2-oxo-acid dehydrogenase complex), suggesting that they might be activated by enhancer-binding proteins (EBP) other than NifA. An in silico search for proteins containing a $\sigma^{54}$-interacting domain allowed us to identify 12 potential EBP encoded in the $B$. japonicum genome (bll0890, blr1896, blr2037, blr3685, blr3731, blr4488, blr4490, blr5735, bll6925, blr7003, blr7130, bll7291). In conclusion, the in-nodule rpoN mutant analysis has led to a substantial expansion of the previously known $\sigma^{54}$ regulon by possible new targets transcribed in planta.

\section{Concluding remarks.}

Our global transcript profile analysis showed i) a massive difference between gene expression under aerobic and symbiotic conditions (66 vs. $34 \%$ of all genes) and ii) a dramatic change $(33 \%)$ in expression when comparing bacteroids with free-living cultures.

1-Aminocyclopropane-1-carboxylate (ACC) is the precursor of ethylene biosynthesis in plants. Rhizobia can degrade ACC by means of ACC deaminase, whereby they overcome the ethylene-mediated inhibition of nodulation (Ma et al. 2003; Uchiumi et al. 2004). In the present work, quite fittingly, the $B$. japonicum ACC deaminase gene (blr0241; acdS) was found to be well-induced in bacteroids (fold change 20.1) and strongly dependent on $\sigma^{54}$ (fold change -73.0 in rpoN $^{-}$bacteroids), and its gene product belonged to those bacteroid proteins detected by proteomics. The ferredoxin encoded by $f d x N$ (bsr1739), which is highly induced in bacteroids (fold change 76) and strongly dependent on $\sigma^{54}$ (fold change -47.8 in rpoN ${ }^{-}$bacteroids), was previously shown to be required for efficient symbiotic nitrogen fixation (Hauser et al. 2007). These are just two of the many examples of the convergence of symbiosis-related genetic and functional information. To provide similar details for every relevant gene goes beyond the scope of this paper. Even more numerous are those genes-several hundred, in fact-for which functional information is either only predictable, at best, or not available at all.

The gene with the highest fold change of expression $($ ect $C$; Table 2) has recently been shown to be a member of the $\mathrm{NifA}+\sigma^{54}$ regulon. Yet, an ectC knock-out mutation did not cause a symbiotic defect (Hauser et al. 2007). Hence, highly induced transcription in bacteroids does not necessarily guarantee symbiotic essentiality of that gene. Nevertheless, while it cannot be expected that all of the newly discovered bacteroidexpressed genes are important or even essential for symbiosis, we are optimistic that our approach will lead to hitherto unexplored facets of bacteroid physiology and biochemistry. In order to track down new symbiotic functions, mutagenesis of all candidate genes followed by adequate phenotypic screens would be the method of choice. Importantly, this would allow an unbiased testing of all candidates, including the many genes implied in symbiosis for the first time here but that lack any functional annotation. Unfortunately, such a high-throughput method for creating and screening rhizobial mutants is not readily available. Instead, we may have to carefully select a smaller number of candidates that promise to be relevant for symbiosis. The integration of results from our global transcriptome comparisons and the phenotypes of specific knock-out mutants together with comparative genomics and data mining by various bioinformatics approaches and assistance from educated guesses on the basis of available literature will hopefully allow us to make such a prioritization. Most promising targets in this respect are probably those genes that have no recognizable, compensatory homologs in the genome and whose functions cannot be by-passed in cells by other means. While we have deliberately focused our initial data analysis on the annotated genes, the tiling design of our custom Affymetrix array, despite its limited resolution, will allow an identification not only of novel genes missed in the original annotation (Hauser et al 2007) but also of potential noncoding RNAs.

\section{MATERIALS AND METHODS}

\section{Bacterial strains and growth conditions.}

Cells of the B. japonicum wild-type 110spc4 (Regensburger and Hennecke 1983) and the $\operatorname{rpoN}_{1+2}$ double mutant strain N50-97 (Kullik et al. 1991) were grown under aerobic and microaerobic conditions in PSY medium (Regensburger and Hennecke 1983) containing $0.1 \%$ L-arabinose and spectinomycin $\left(100 \mu \mathrm{g} \mathrm{ml}^{-1}\right)$. Aerobic cultures were grown with rigorous shaking $(180 \mathrm{rpm})$ in 5-liter Erlenmeyer flasks containing 200 $\mathrm{ml}$ of medium. Microaerobic cultures were grown under a nitrogen gas atmosphere that contained $0.5 \%$ oxygen with moderate shaking $(80 \mathrm{rpm})$ in $500-\mathrm{ml}$ rubber-stoppered serum bottles containing $25 \mathrm{ml}$ of medium. The gas phase $\left(0.5 \% \mathrm{O}_{2}, 99.5 \%\right.$ $\mathrm{N}_{2}$ ) was exchanged every 8 to $14 \mathrm{~h}$.

\section{Plant growth conditions and inoculation.}

Infection of soybean seedlings (Glycine max L. Merr., cv. Williams; provided by D. N. Navarro and F. Temprano, CIFA- 
Las Torres Tomejil, Spain) and determination of nitrogenase activity in bacteroids were performed as described previously (Göttfert et al. 1990). Nodules from five plants were collected for each GeneChip hybridization experiment. For studies on the kinetics of bacteroid development, nodules were harvested at 10 , 13, 21, and 31 dpi and immediately frozen in liquid nitrogen.

\section{RNA purification, cDNA synthesis, labeling,} and hybridization.

Cells were grown to mid-exponential phase (optical density at $600 \mathrm{~nm}$ of 0.4 to 0.5 ). For harvesting, cultures were rapidly transferred to cold tubes containing one tenth of the culture volume of "stop solution" (10\% Tris-HCl-buffered phenol [pH

Table 4.The 61 genes that showed decreased expression in nodules infected by an $r p o N_{1+2}$ mutant strain and which have a predicted RpoN binding site in the promoter region

\begin{tabular}{|c|c|c|c|}
\hline Gene number ${ }^{\mathrm{a}}$ & Description $^{b}$ & Gene name ${ }^{c}$ & Fold change $^{d}$ \\
\hline blr0612* & Nitrogen regulatory protein PII & $g \ln K$ & -16.8 \\
\hline blr0613* & Ammonium transporter & $a m t B$ & -11.0 \\
\hline bllo889* & Putative transport protein & - & -7.4 \\
\hline blr1036* & $\mathrm{ABC}$ transporter substrate-binding protein & - & -5.3 \\
\hline blr1719* & Molybdenum transport system permease protein & $\bmod B$ & -20.4 \\
\hline blr1726* & Unknown protein & - & -120.0 \\
\hline blr1747* & Iron-molybdenum cofactor processing protein & nifX & -43.1 \\
\hline blr1765* & Ferredoxin & fer2 & -41.0 \\
\hline blr1879* & Hypothetical protein & - & -35.1 \\
\hline blr1954* & Unknown protein & - & -155.0 \\
\hline blr1971* & Putative peptidase & - & -22.1 \\
\hline blr1992* & Unknown protein & - & -90.1 \\
\hline blr2011* & Unknown protein & - & -82.0 \\
\hline blr2036* & Oxidoreductase & fix $R$ & -3.4 \\
\hline bll2085* & Hypothetical protein & - & -27.5 \\
\hline blr2143* & Similar to cytochrome $\mathrm{P} 450$-family protein & - & -82.6 \\
\hline bs $12575^{*}$ & Hypothetical protein & - & -32.6 \\
\hline blr2725* & Hypothetical protein & - & -11.6 \\
\hline bll3193* & Unknown protein & - & -74.6 \\
\hline bl13316 & $\mathrm{ABC}$ transporter substrate-binding protein & - & -5.6 \\
\hline blr3337 & $\mathrm{ABC}$ transporter substrate-binding protein & - & -2.6 \\
\hline blr3338 & $\mathrm{ABC}$ transporter permease protein & - & -2.2 \\
\hline blr3341* & $\mathrm{ABC}$ transporter substrate-binding protein & - & -4.6 \\
\hline blr3342 & $\mathrm{ABC}$ transporter permease protein & - & -2.2 \\
\hline bl13363 & Unknown protein & - & -9.7 \\
\hline blr3677* & Putative monooxygenase component & - & -57.8 \\
\hline blr3719 & Hypothetical protein & - & -358.4 \\
\hline blr3720 & Probable pyruvate dehydrogenase & - & -7.5 \\
\hline blr3721 & Dihydrolipoamide $S$-acetyltransferase & aceF & -11.0 \\
\hline blr3722 & Dihydrolipoamide dehydrogenase & lpd & -20.0 \\
\hline blr4169* & Glutamine synthetase II & $g \ln I I$ & -5.9 \\
\hline bll4384* & Probable substrate-binding protein & - & -20.1 \\
\hline blr4624 & Hypothetical protein & - & -3.7 \\
\hline bll4798 & Putative glutaminase & - & -2.8 \\
\hline bl14943 & ATP-dependent Clp protease, ATP-binding subunit & $\operatorname{clp} X$ & -2.2 \\
\hline blr5374* & Hypothetical protein & - & -7.9 \\
\hline blr5573 & $\mathrm{ABC}$ transporter ATP-binding protein & - & -2.7 \\
\hline blr5574 & $\mathrm{ABC}$ transporter substrate-binding protein & - & -8.9 \\
\hline blr5598 & $\mathrm{ABC}$ transporter permease protein & - & -4.0 \\
\hline blr5599 & $\mathrm{ABC}$ transporter permease protein & - & -2.2 \\
\hline bl15733* & Nitrate $\mathrm{ABC}$ transporter permease protein & $n r t B$ & -3.9 \\
\hline bll5734* & $\mathrm{ABC}$ transporter nitrate-binding protein & $n r t A$ & -23.5 \\
\hline bl16091 & $\mathrm{ABC}$ transporter ATP-binding protein & - & -2.6 \\
\hline bs16119 & Unknown protein & - & -2.4 \\
\hline blr6145* & C4-dicarboxylate transport protein & $d c t A$ & -2.4 \\
\hline bll6414 & Transcriptional regulatory protein LuxR family & - & -3.1 \\
\hline bl16702 & Glutathione $S$-transferase & - & -6.3 \\
\hline bs16929 & Hydrogenase expression/formation protein & hypC & -3.4 \\
\hline bl16936 & HupH protein & hирH & -6.7 \\
\hline bl16937 & HupG protein & hupG & -3.4 \\
\hline bll6939* & HupD protein & hupD & -48.5 \\
\hline bll6940* & HupC protein & hupC & -61.7 \\
\hline bll6941* & Uptake hydrogenase large subunit & hupL & -33.8 \\
\hline bll6942* & Uptake hydrogenase precursor & hupS & -178.3 \\
\hline blr6953* & Molybdenum ABC transporter ATP-binding protein & $\bmod C$ & -5.0 \\
\hline blr6955* & Unknown protein & - & -2.8 \\
\hline bll7176* & Hypothetical protein & - & -3.0 \\
\hline bll7178* & Hypothetical protein & - & -5.7 \\
\hline bll7179* & Putative $N$-methylhydantoinase B & - & -3.2 \\
\hline bll7180* & Hydantoin utilization protein & - & -4.3 \\
\hline blr7289* & Putative alkanal monooxygenase & $\operatorname{luxA2}$ & -14.7 \\
\hline
\end{tabular}

a Asterisks (*) indicate the RpoN-dependent genes activated by NifA in anaerobiosis. Nomenclature according to Kaneko and associates (2002).

${ }^{\mathrm{b}}$ Gene description according to Kaneko and associates (2002).

c Gene name according to the EMBL-EBI database.

${ }^{\mathrm{d}}$ Fold change of expression, comparing $r p o N_{1+2}$ mutant bacteroids with wild-type bacteroids. 
8 ] in ethanol), were centrifuged for $5 \min \left(10,800 \times g, 4^{\circ} \mathrm{C}\right)$, the supernatant was decanted, and cells were frozen in liquid nitrogen and stored at $-80^{\circ} \mathrm{C}$. For RNA isolation from symbiotically grown bacteria, approximately 10 frozen nodules were placed in a 2-ml Eppendorf tube and were disrupted and homogenized using a TissueLyzer (Qiagen, Valencia, CA, U.S.A.) (three times for $50 \mathrm{~s} ; 30$ Hertz) with a tungsten carbide bead (3 $\mathrm{mm}$; Qiagen). Total RNA was isolated from the disrupted nodule material and from free-living bacterial cultures with the hot phenol-extraction procedure described previously (Babst et al. 1996). RNA purification, first-strand cDNA synthesis, fragmentation, and terminal labeling were done as previously described (Hauser et al. 2007). Fragmented cDNA generated from bacteroids were end-labeled in a final volume of $50 \mu \mathrm{l}$, using double amounts of labeling reagent and terminal deoxynucleotide transferase as compared with the previous protocol. Hybridization and washing procedures were carried out as described (Hauser et al. 2007). Between 2 and $2.5 \mu \mathrm{g}$ of cDNA generated from culture-grown bacteria and 6 and $7.5 \mu \mathrm{g}$ (for wild-type and $\mathrm{rpoN}_{1+2}$-deficient bacteroids, respectively) of total bacteroid cDNA were hybridized to the GeneChips. The amount of bacteroid cDNA was estimated from the proportion of bacterial/plant RNA in nodules, which was roughly 1:2 and 1:3 for wild-type and $r p o N_{1+2}$-deficient bacteroids, respectively (Bioanalyzer, Agilent technologies, Palo Alto, CA, U.S.A.). As control, an equal amount of bacterial cDNA was loaded on the GeneChip, and we assessed the constitutive expression of the primary sigma factor $\operatorname{sig} A$. In order to determine the extent of cross-hybridization of the GeneChip probes with plant RNA, RNA was isolated from the roots of soybean plants as described above, and cDNA was fragmented and labeled according to the protocol for free-living bacteria. A custom-made Affymetrix GeneChip representing 8,266 annotated $B$. japonicum genes and 5,261 intergenic sequences on both strands was used in this study (Hauser et al. 2007). Importantly, the whole set of B. japonicum oligonucleotide probes had been pruned against soybean EST sequences to minimize cross-hybridization with plant RNA. At least six biological replicates were analyzed for the wild type and the $\operatorname{rpoN}_{1+2}$ mutant N50-97 grown under different free-living conditions. For the timecourse experiments with nodulated soybean plants (discussed above), at least two biological replicates were examined.

\section{Data processing, normalization, and further analyses.}

Hybridization signals were processed using the Gene Chip Operating System software from Affymetrix. Signals were scaled to a target signal intensity of 500 by using all probe sets. Data were further analyzed using the GeneSpring gene expression analysis software version 7.3 (Agilent). To minimize false positives, very stringent criteria were applied. For culture-grown bacteria or bacteroids, only those genes that are "present" (i.e., expressed, based on the detection $P$-value $\leq$ 0.06) (Hauser et al. 2007) in $80 \%$ of all replicates were further considered. Moreover, we excluded all genes in analyses with bacteroids for which the expression was not at least two times higher than in the control hybridizations with root material only. Thereby, we excluded those signals that might have originated from cross-hybridization with plant RNA. For these cross-hybridization control experiments, the amount of plant RNA was normalized to the signal of the Glycine max $18 \mathrm{~S}$ rRNA. For experiments comparing different conditions among culture-grown bacteria or bacteroids, each chip was normalized to the median. Values below 0.01 were set to 0.01 . Importantly, for the comparison of the expression profiles of culture-grown bacteria with bacteroids, no median normalization was applied, since the majority of genes are down-regulated in the bacteroids, and the signal distribution in these two conditions was very different (Supplemental Figure 1). Therefore the assumptions underlying a median normalization do not apply. For statistical comparisons, the Wilcoxon rank-sum test was applied with a $P$-value threshold of 0.01 . If not possible due to fewer numbers of biological replicas $(<5)$, the student $t$-test with a $P$ value threshold of 0.01 was applied. Genes were considered as differentially expressed if the fold change was $>2$ when comparing different conditions among culture-grown bacteria or symbiotic bacteria.

For each gene, we computed the percentage of up- and downregulated neighboring genes on the chromosome (Fig. 3). The neighboring genes were defined by a sliding window containing 50 successive genes on the chromosome. The $\mathrm{G}+\mathrm{C}$ content of a chromosomal position was computed as the percentage of $\mathrm{G}$ and $\mathrm{C}$ nucleotides within a window of 1,000 nucleotides surrounding the chromosomal position.

For a functional classification of the differentially expressed genes, we used the Kazusa functional gene classification for $B$. japonicum (RhizoBase website). All entries were categorized according to 14 functional categories and an additional category containing genes encoding hypothetical proteins. Hypergeometric tests (Fisher's exact test) were used to identify functional groups that are significantly over- or underrepresented among the differentially expressed genes relative to all genes. Only categories with a $P$-value $\leq 0.01$ were considered as being significantly over- or underrepresented. The hierarchical clustering of genes (Fig. 4) was performed in GeneSpring 7.3.1. As a similarity measure, the Euclidean distance was used, and clusters were aggregated using the complete linkage algorithm. NifA and RpoN $\left(\sigma^{54}\right)$ consensus DNA-binding sequences in the promoter regions of selected genes were identified using position-specific frequency matrices (Hauser et al. 2007). EBP with a $\sigma^{54}$ interacting domain in $B$. japonicum genome were predicted using the Interpro database.

\section{ACKNOWLEDGMENTS}

We thank A. Patrignani, U. Wagner and R. Schlapbach of the Functional Genomics Center Zurich (FGCZ) for help and advice with chip hybridization experiments and M. Friberg for performing the motif prediction for RpoN $\left(\sigma^{54}\right)$ consensus DNA-binding sequences. This work was supported by a grant from the Swiss National Foundation for Scientific Research Acquisition of GeneChips was made possible through finances from the ETH Zurich and the FGCZ.

\section{LITERATURE CITED}

Babst, M., Hennecke, H., and Fischer, H. M. 1996. Two different mechanisms are involved in the heat-shock regulation of chaperonin gene expression in Bradyrhizobium japonicum. Mol. Microbiol. 19:827-839.

Barnett, M. J., Toman, C. J., Fisher, R. F., and Long, S. R. 2004. A dualgenome symbiosis chip for coordinate study of signal exchange and development in a prokaryote-host interaction. Proc. Natl. Acad. Sci. U.S.A. 101:16636-16641.

Batut, J., and Boistard, P. 1994. Oxygen control in Rhizobium. Antonie Van Leeuwenhoek 66:129-150.

Bauer, E., Kaspar, T., Fischer, H. M., and Hennecke, H. 1998. Expression of the fixR-nifA operon in Bradyrhizobium japonicum depends on a new response regulator, RegR. J. Bacteriol. 180:3853-3863.

Becker, A., Berges, H., Krol, E., Bruand, C., Rüberg, S., Capela, D., Lauber, E., Meilhoc, E., Ampe, F., de Bruijn, F. J., Fourment, J., Francez-Charlot, A., Kahn, D., Kuster, H., Liebe, C., Pühler, A., Weidner, S., and Batut, J. 2004. Global changes in gene expression in Sinorhizobium meliloti 1021 under microoxic and symbiotic conditions. Mol. Plant-Microbe Interact. 17:292-303.

Capela, D., Filipe, C., Bobik, C., Batut, J., and Bruand, C. 2006. Sinorhizobium meliloti differentiation during symbiosis with alfalfa: A transcriptomic dissection. Mol. Plant-Microbe Interact. 19:363-372.

Delgado, M. J., Tresierra-Ayala, A., Talbi, C., and Bedmar, E. J. 2006. Functional characterization of the Bradyrhizobium japonicum modA and $\bmod B$ genes involved in molybdenum transport. Microbiology 152:199-207. 
Dixon, R., and Kahn, D. 2004. Genetic regulation of biological nitrogen fixation. Nat. Rev. Microbiol. 2:621-631.

Downie, J. A. 2005. Legume haemoglobins: Symbiotic nitrogen fixation needs bloody nodules. Curr. Biol. 15:R196-198.

Eichhorn, E., van der Ploeg, J. R., and Leisinger, T. 2000. Deletion analysis of the Escherichia coli taurine and alkanesulfonate transport systems. J. Bacteriol. 182:2687-2695.

Fischer, H. M. 1994. Genetic regulation of nitrogen fixation in rhizobia. Microbiol Rev. 58:352-386.

Gage, D. J. 2004. Infection and invasion of roots by symbiotic, nitrogenfixing rhizobia during nodulation of temperate legumes. Microbiol. Mol. Biol. Rev. 68:280-300.

Göttfert, M., Grob, P., and Hennecke, H. 1990. Proposed regulatory pathway encoded by the nodV and nodW genes, determinants of host specificity in Bradyrhizobium japonicum. Proc. Natl. Acad. Sci. U.S.A. 87:2680-2684.

Göttfert, M., Röthlisberger, S., Kündig, C., Beck, C., Marty, R., and Hennecke, H. 2001. Potential symbiosis-specific genes uncovered by sequencing a 410-kilobase DNA region of the Bradyrhizobium japonicum chromosome. J. Bacteriol. 183:1405-1412.

Green, L. S., Li, Y., Emerich, D. W., Bergersen, F. J., and Day, D. A. 2000. Catabolism of alpha-ketoglutarate by a sucA mutant of Bradyrhizobium japonicum: Evidence for an alternative tricarboxylic acid cycle. J Bacteriol. 182:2838-2844.

Hauser, F., Lindemann, A., Vuilleumier, S., Patrignani, A., Schlapbach, R., Fischer, H. M., and Hennecke, H. 2006. Design and validation of a partial-genome microarray for transcriptional profiling of the Bradyrhizobium japonicum symbiotic gene region. Mol. Genet. Genomics 275:5567.

Hauser, F., Pessi, G., Friberg, M., Weber, C., Rusca, N., Lindemann, A., Fischer, H. M., and Hennecke, H. 2007. Dissection of the Bradyrhizobium japonicum NifA $+\sigma^{54}$ regulons, and identification of a ferredoxin gene $(f d x N)$ for symbiotic nitrogen fixation. Mol. Genet. Genomics 278:255-271.

Kaneko, T., Nakamura, Y., Sato, S., Minamisawa, K., Uchiumi, T., Sasamoto, S., Watanabe, A., Idesawa, K., Iriguchi, M., Kawashima, K., Kohara, M., Matsumoto, M., Shimpo, S., Tsuruoka, H., Wada, T., Yamada, M., and Tabata, S. 2002. Complete genomic sequence of nitrogen-fixing symbiotic bacterium Bradyrhizobium japonicum USDA110. DNA Res. 9:189-197.

Krause, A., Doerfel, A., and Göttfert, M. 2002. Mutational and transcriptional analysis of the type III-secretion system of Bradyrhizobium japonicum. Mol. Plant-Microbe Interact. 15:1228-1235.

Krol, E., and Becker, A. 2004. Global transcriptional analysis of the phosphate starvation response in Sinorhizobium meliloti strains 1021 and 2011. Mol. Genet. Genomics 272:1-17.

Kullik, I., Fritsche, S., Knobel, H., Sanjuan, J., Hennecke, H., and Fischer, H. M. 1991. Bradyrhizobium japonicum has two differentially regulated, functional homologs of the sigma 54 gene $(r p o N)$. J. Bacteriol. 173:1125-1138.

Lodwig, E. M., and Poole, P. 2003. Metabolism of Rhizobium bacteroids. Crit. Rev. Plant Sci. 22:37-78.

Loh, J., and Stacey, G. 2003. Nodulation gene regulation in Bradyrhizobium japonicum: A unique integration of global regulatory circuits. Appl. Environ. Microbiol. 69:10-17.

Long, S. R. 2001. Genes and signals in the Rhizobium-legume symbiosis. Plant Physiol. 125:69-72.

Ma, W., Guinel, F. C., and Glick, B. R. 2003. Rhizobium leguminosarum biovar viciae 1-aminocyclopropane-1-carboxylate deaminase promotes nodulation of pea plants. Appl. Environ. Microbiol. 69:4396-4402.

Maier, R. J., Graham, L., Keefe, R. G., Pihl, T., and Smith, E. 1987. Bradyrhizobium japonicum mutants defective in nitrogen fixation and molybdenum metabolism. J. Bacteriol. 169:2548-2554.

Minder, A. C., de Rudder, K. E., Narberhaus, F., Fischer, H. M.,
Hennecke, H., and Geiger, O. 2001. Phosphatidylcholine levels in Bradyrhizobium japonicum membranes are critical for an efficient symbiosis with the soybean host plant. Mol. Microbiol. 39:1186-1198.

Nellen-Anthamatten, D., Rossi, P., Preisig, O., Kullik, I., Babst, M., Fischer, H. M., and Hennecke, H. 1998. Bradyrhizobium japonicum FixK $_{2}$, a crucial distributor in the FixLJ-dependent regulatory cascade for control of genes inducible by low oxygen levels. J. Bacteriol. 180:5251-5255.

Pauly, N., Pucciariello, C., Mandon, K., Innocenti, G., Jamet, A., Baudouin, E., Hérouart, D., Frendo, P., and Puppo, A. 2006. Reactive oxygen and nitrogen species and glutathione: Key players in the legume-Rhizobium symbiosis. J. Exp. Bot. 57:1769-1676.

Poole, P. S., and Allaway, D. A. 2000. Carbon and nitrogen metabolism in Rhizobium. Adv. Microb. Physiol. 43:117-163.

Preisig, O., Zufferey, R., Thöny-Meyer, L., Appleby, C. A., and Hennecke, H. 1996. A high-affinity $c b b_{3}$-type cytochrome oxidase terminates the symbiosis-specific respiratory chain of Bradyrhizobium japonicum. J. Bacteriol. 178:1532-1538.

Prell, J., and Poole, P. 2006. Metabolic changes of rhizobia in legume nodules. Trends Microbiol. 14:161-168.

Regensburger, B., and Hennecke, H. 1983. RNA polymerase from Rhizobium japonicum. Arch. Microbiol. 135:103-109.

Rudolph, G., Semini, G., Hauser, F., Lindemann, A., Friberg, M., Hennecke, H., and Fischer, H. M. 2006. The iron control element, acting in positive and negative control of iron-regulated Bradyrhizobium japonicum genes, is a target for the Irr protein. J. Bacteriol. 188:733-744.

Sarma, A. D., and Emerich, D. W. 2005. Global protein expression pattern of Bradyrhizobium japonicum bacteroids: A prelude to functional proteomics. Proteomics 5:4170-4184.

Sarma, A. D., and Emerich, D. W. 2006. A comparative proteomic evaluation of culture-grown vs nodule-isolated Bradyrhizobium japonicum. Proteomics 6:3008-3028.

Sciotti, M. A., Chanfon, A., Hennecke, H., and Fischer, H. M. 2003. Disparate oxygen responsiveness of two regulatory cascades that control expression of symbiotic genes in Bradyrhizobium japonicum. J. Bacteriol. 185:5639-5642.

Uchiumi, T., Ohwada, T., Itakura, M., Mitsui, H., Nukui, N., Dawadi, P., Kaneko, T., Tabata, S., Yokoyama, T., Tejima, K., Saeki, K., Omori, H., Hayashi, M., Maekawa, T., Sriprang, R., Murooka, Y., Tajima, S., Simomura, K., Nomura, M., Suzuki, A., Shimoda, Y., Sioya, K., Abe, M., and Minamisawa, K. 2004. Expression islands clustered on the symbiosis island of the Mesorhizobium loti genome. J. Bacteriol. 186:2439-2448.

Yang, J., Sangwan, I., Lindemann, A., Hauser, F., Hennecke, H., Fischer, H. M., and O'Brian, M. R. 2006a. Bradyrhizobium japonicum senses iron through the status of haem to regulate iron homeostasis and metabolism. Mol. Microbiol. 60:427-437.

Yang, J., Sangwan, I., and O'Brian M, R. 2006b. The Bradyrhizobium japonicum Fur protein is an iron-responsive regulator in vivo. Mol Genet Genomics 276:555-564.

Yurgel, S. N., and Kahn, M. L. 2004. Dicarboxylate transport by rhizobia FEMS (Fed. Eur. Microbiol. Soc.) Microbiol. Rev. 28:489-501.

\section{AUTHOR-RECOMMENDED INTERNET RESOURCES}

Affymetrix GeneChip website: http://www.affymetrix.com

EMBL-EBI database: www.ebi.ac.uk/embl

NCBI Gene Expression Omnibus (GEO) database:

www.ncbi.nlm.nih.gov/geo

NCBI pairwise genome comparison webpage: www.ncbi.nlm.nih.gov/sutils/geneplot.cgi

RhizoBase database: bacteria.kazusa.or.jp/rhizobase

RhizoDB website: rhizo.bham.ac.uk 